\title{
Phonosemantic shape-sound correlates
}

Elena Besedina

Dept of Foreign Languages, Saint Petersburg Electrotechnical University, Russia

https://doi.org/10.36505/ExLing-2019/10/0006/000368

\begin{abstract}
This paper focuses on the study of sound symbolism and presents the results of two complementary psycholinguistic experiments carried out with 360 male and female Russian native speakers. The data were analysed by statistical methods of experimental data processing, with a relatively large final sample size $(n \geq 30)$ and prove the existence of an unambiguous phonosemantic correlation between the rounded shape of an object and the labial phonotype. The obtained results are strikingly consistent with those of a previously conducted structural analysis of the corpus of 95 Russian words denoting 'roundness'.
\end{abstract}

Key words: labial phonotype, psycholinguistics, shape-sound correlates, sound symbolism

\section{Introduction: psycholinguistic experimental data}

The association between sound and meaning known as sound symbolism is important for cognitive linguistic theories. Though it concerns the so-called peripheral system of any natural language, it is closely connected with such fundamental problems as arbitrariness/nonarbitrariness of the language sign, presenting a very strong counterargument against the thesis about arbitrary relations between a signifiant and a signifié, and is highly relevant to the studies of language origin and development.

Throughout the history of studying the issue many researchers who looked at the vocabularies of different natural languages pointed out the special role that certain labial phonemes have in words denoting rounded, spherical, protruding or bulging objects (e.g. Gonda 1940; Ultan 1978; Voronin 2006; Makarov 2017).

Psycholinguistic experimental studies have also proved to be an effective instrument to demonstrate a consistent correspondence between sound and meaning. A certain correlation between labial phonemes and the notion of roundness was also proven experimentally, the classical example being the world-famous 'maluma-takete' experiment by W. Kohler (Kohler 1929) which was followed by a number experiments employing similar techniques (Fox Elena Besedina 1935; Ohwaki, Sato 1954; O’Boyle, Tarte 1982; Managhan, Mattock, Walker 2012; Ozturk, Krehm, Vouloumanos 2013).

ExLing 2019: Proceedings of $10^{\text {th }}$ International Conference of Experimental Linguistics, 25-27 September 2019, Lisbon, Portugal 


\section{Material, method and data procedure}

This study aims at proving the existence of a phonosemantic correlation between the rounded shape of an object and the labial phonotype by means of two complimentary psycholinguistic experiments.

In the first experiment the participants (300 male and female native Russian speakers aged 14-24 years) were asked to construct a word for some rounded object according to the CVC model, each giving one and only one response.

The second experiment was carried out with 60 male and female Russian native speakers aged 5-9 years. Due to their specific stage of language development, this age group seemed perfect for that kind of experiment. This time the respondents were asked to "invent" a word for a rounded object made of wax with no restrictions whatsoever. Like in the previous experiment, each child responded only once.

To assess the results statistically, the data obtained in each experiment were analysed by statistical methods of experimental data processing that offer reliable estimates of distribution of a discrete random variable, with a relatively large final sample size $(n \geq 30)$. These important parameters include: $\bar{x}$-sample mean value of a random variable and its confidence interval, $S_{x}-$ (sample) standard deviation, $S_{x} / \sqrt{ }_{n}$ - Root Mean Square Error (RMSE), where $n$ is the sample size, and $\mathrm{v}_{\mu}$ the coefficient of variation of the mean value of a random variable.

\section{Results and discussion}

\section{First experiment}

In the first experiment, the respondents produced $300 \mathrm{CVC}$ words to name a rounded object. The analysis showed that $91 \%$ of these words contained at least one labial phoneme, $29 \%$ contained more than one labial phoneme, a quarter of all polylabial words consisting of labial phonemes only. It also interesting that $72 \%$ of all constructed words begin with a labial consonant. The most obvious examples of the words constructed by the respondents are following: боп /'bop/, бот /'bot/, буп /'bup/, бун /'bun/, воб /'vop]/, воф /'vof/, вом /'vom/, мом /'mom/, пом /'pom/ пон /'pon/, фом /'fom/, фoф /'fof/, etc. These words were compared with 412 CVC Russian words obtained by continuous sampling from The Russian Language Dictionary. Further statistical analysis showed that the frequency of the occurrence of the labial phonotype in the analysed words on average exceeds the expectation of this phonotype in Russian words of the CVC model by 1.46 (1.48 for vowels and 1, 43 for consonants). As far as the figures for concrete phonemes are concerned, we can discuss only some of them as the values as the rest of them are not reliable enough to make any suggestions. These phonemes are /b/, /o/ and $/ \mathrm{m} /$ and they exceed the frequency of their occurrence by $2.41 ; 2.05$ and 1.96 , respectively. 


\section{Second experiment}

In the second experiment, participants produced 60 words to name the rounded object they were shown, and all the words produced contained at least one labial phoneme and $80 \%$ of the words were polylabial. The following examples illustrate the results of the second experiment: бофа /'bofa/, вома /'voma/, вуба /'vuba/, курука /ku'ruka/, кума /'luma/, муфи /'mufi/, фом /'fom/, фом /'fom/), чумбак / 5 um'bak/, чучук / $\mathrm{t}$ u't $\mathrm{t}$ uk /. Using the same formalism, the comparison of the constructed words and sample of 700 Russian nouns obtained by means of the random number generator revealed that the frequency of the labial phonotype occurrence in the words constructed by young children on average exceeds the expectation of this phonotype in Russian words by 1.73 (2.0 for vowels and 1.54 for consonants). It was also interesting to analyse the relative occurrence frequency of words with labial phonemes. The analysis demonstrated that that the frequency of the occurrence of the labial phonotype in these words on average exceeds the expectation of this phonotype in Russian words by 1.43, while for polylabial words this figure is even higher and equals 2.33. The results of these two experiments seem strikingly consistent and show with a 95\% confidence level that Russian native speakers exhibit a positive non-arbitrary correlation between the labial phonotype and the rounded shape of an object.

The obtained results correspond well with those of the phonosemantic analysis of the corpus of 95 words denoting 'roundness' the Russian language. When analysed by the same standard statistical methods, they manifested the frequency of labial prototype occurrence that exceeds by 1.91 (2.43 for vowels and 1.61 for consonants) the corresponding variable for the random sample (Besedina 2016).

\section{Conclusion}

The employment of statistical methods not only made apparent the correlation between the designation of 'roundness' and the labial phonotype with Russian native speakers but also demonstrated the efficiency and reliability of this instrument within the framework of this particular problem.

To draw more general conclusions about this association, it is necessary to conduct experiments with groups of respondents of various unrelated languages to find out whether this association between 'roundness' and the labial phonotype is a universalia or at least a frequentalia of sound symbolic character.

\section{Acknowledgements}

The author would like to express sincere appreciation of the assistance in conducting the second experiment provided by the administration of secondary school No. 74 (St. Petersburg). 


\section{References}

Besedina, E. 2016. Sound Symbolism in Designation of Roundness. In: Brodovich, O. (ed.), Anglistics of the XXI Century. Phonosemantics 2, 20-24. SPb., Russia.

Fox, Ch. 1935. An experimental study of naming. American J. of Psychol. 47, 545579.

Gonda J. 1940. Some remarks on onomatopoeia, sound symbolism and word formation a propes of the theories of C. N. Maxwell. Tijdschrift voor indisher taal-, land- en volkenkunder 80, 133-210.

Kohler, W. 1929. Gestalt psychology. NY: H. Liveright, 1929.

Makarov, A. A.2017 Kompjutornyi analiz raspredeleniya phonemotipov v slovakh oboznachayustchikh 'okrugloye' i 'bolshoye' (Компьюторный анализ распределения фонемотипов в словах, обозначающих «округлое» и «большое». In: Flaksman, M. (ed.), Proceedings of the VI Interacademic

Conference 'Current Issues of Linguistics', 296-302. SPb., Russia.

Managhan, P., Mattock, K., Walker, P. 2012. The role of sound symbolism in word learning. J. Exp. Psychol.: Learn. Mem. Cogn. 38, 1152-1164.

O’Boyle, M., Tarte, R. 1980. Implications for phonetic symbolism: the relationships between pure tones and geometric figures. J. of Psychol. Research 9, 535-543.

Ohwaki, Y., Sato, K. 1954. An experimental study on the psychological relationship between visual and auditory stimuli. Tonoku Psycholinguistic Folia 28, 58-71.

Ozturk, O., Krehm, M., Vouloumanos, A. 2013. Sound symbolism in infancy: evidence for sound-shape cross-modal correspondences in 4-month-olds. J. Exp. Child Psychol. 114, 173-186.

Voronin, S. V. 2006. Osnovy phonosemantiki (Основы фоносемантики). М.: $\Lambda$ EHAHА.

Ultan, R 1978. Size-sound symbolism. Universals of human language 2, 523-568. 